\title{
PENGEMBANGAN MODUL DETEKSI DINI PEMANTAUAN BALITA STUNTING DI POSYANDU
}

\author{
${ }^{1}$ Samuel Isnar, ${ }^{2}$ Nurul Alfiah \\ ${ }^{1,2)}$ Prodi Gizi Cirebon Poltekkes Kemenkes Tasikmalaya \\ wairisal29@yahoo.co.id
}

Diterima: 30 Oktober 2018

Direvisi: 16 November 2018

Diterbitkan:07 Januari 2019

\begin{abstract}
The prevalence of stunting in children under five which tends to increase both at the city district level to the national level, the results of the Basic Health Research Survey (Riskesdas) in 2013 stunting increased from 35.6\% in 2010 to $37.2 \%$ or an increase of 2, 4\%, with details of $18.0 \%$ very short and $19.2 \%$ short. The impact of the problem stunting is obesity and loss of $I Q$ points, a study by the University of North Carolina found that IQ scores for children were stunting eight-year-old11 points lower than for non-children stunting. World Health Assembly (WHA) targets that by 2025 the decline under five prevalence is stunting $40 \%$ of the current prevalence. In order to achieve this target, all elements must be involved in all city districts to the community, especially posyandu cadres.

As many as $53.3 \%$ of cadres have education levels of cadres who take module trials are high school, with ages ranging from 31 to 60 years, 93.3\% of cadres judge according to the subject headings with the contents of the module. $73.3 \%$ can understand the contents of module 2. After a focus group discussion that feels difficult to understand is the calculation of age by method 2 , $67.7 \%$ of the posyandu cadres assess the module as very important to them and only $33.3 \%$ say it is important, and $46.7 \%$ assessed that it is necessary to carry out early detection of the incidence of stunting in the Posyandu.
\end{abstract}

Keywords : Stunting, Kader Posyandu

\begin{abstract}
ABSTRAK
Prevalensi stunting pada balita yang cenderung meningkat baik pada tingkat kabupaten kota sampai tingkat nasional, hasil Survei Riset Kesehatan Dasar (Riskesdas) pada tahun tahun 2013 stunting mengalami peningkatan dari 35,6\% pada tahun 2010 menjadi 37,2\% atau peningkatan sebesar 2,4\%, dengan rincian 18,0 \% sangat pendek dan 19,2\% pendek. Dampak yang ditimbulkan dari masalah stunting adalah obesitas dan kehilangan IQ point, hasil penelitian oleh University of North Carolina, menemukan bahwa skor IQ anak-anak stunting usia delapan tahun lebih rendah 11 point dibandingkan dengan anak-anak yang tidak stunting. World Health Assembly (WHA) menargetkan pada tahun 2025 penurunan prevalensi balita stunting sebesar $40 \%$ dari prevalensi saat ini, untuk mencapai target tersebut semua unsur harus dilibatkan semua kabupaten kota sampai pada masyarakat, hususnya kader posyandu. .

Sebanyak 53,3 \% kader memiliki tingkat pendidikan kader yang mengikuti uji coba modul adalah SMA, dengan usia berkisar antara 31 sampai dengan 60 tahun, 93,3 \% kader menilai sesuai antara Judul pokok bahasan dengan isi modul. 73,3\% dapat memahami isi dari modul 2. Setelah dilakukan focus group discussion yang merasa sulit dipahami adalah perhitungan umur dengan metode $2,67,7 \%$ kader posyandu menilai modul sangat penting bagi mereka dan hanya 33,3\% yang mengatakan penting, dan 46,7 \% menilai perlu dilaksanakan deteksi dini kejadian stunting di Posyandu.
\end{abstract}

Kata Kunci : Stunting, Kader Posyandu 


\section{PENDAHULUAN}

Hasil Survei Riset Kesehatan Dasar (Riskesdas) tahun 2010 prevalensi stunting 35,6\%, artinya dalam kurun waktu tiga tahun terjadi penurunan sebesar 1,2\%( Litbangkes 2010). Tahun 2013 dari hasil survei Riskesdas prevalensi stunting mengalami peningkatan dari $35,6 \%$ pada tahun 2010 menjadi 37,2\% atau peningkatan sebesar 2,4\%, dengan rincian 18,0 \% sangat pendek dan $19,2 \%$ pendek.( Litbangkes,2013)

Dampak yang ditimbulkan dari masalah stunting adalah obesitas, anak stunting memiliki risiko 2,7 kali menjadi obesitas dari anak yang tidak stunting (Isabel Bove,2012). Selain itu stunting menyebabkan serangkaian perubahan penting seperti pengeluaran energi yang lebih rendah, lebih rentan terhadap efek dari diet tinggi lemak, rendah lemak oksidasi serta gangguan metabolisme lemak, sehingga potensi kenaikan berat badan tidak terbatas (Ghaida Yasmin at al,2014). Dampak yang sangat penting menurut UNICEF dari hasil studi di Cebu oleh University of North Carolina, menemukan bahwa skor IQ anak-anak stunting usia delapan tahun lebih rendah 11 point dibandingkan dengan anak-anak yang tidak stunting(Unicef, 1998).

World Health Assembly (WHA) menargetkan pada tahun 2025 penurunan prevalensi balita stunting sebesar $40 \%$ dari prevalensi saat ini, untuk mencapai target tersebut semua unsur harus dilibatkan baik dari pusat, provinsi, kabupaten/kota sampai ditingkat masyarakat. Upaya yang harus dilakukan ditingkat masyarakat dalam menurunankan prevalensi stunting, yaitu melalui meningkatkan partisipasi masyarakat, agar merasa memiliki dan berkontribusi dalam program penangulangan stunting, atau dapat pula melalui pemberdayaan kelompokkelompok yang ada (WHO,2013). Kegiatan yang telah dilaksanakan di Indonesia berupa pemantauan status gizi, dan dapat diartikan sebagai penilaian status gizi, karena kegiatan ini dilaksanakan hanya setahun sekali, pada kabupaten atau kota yang terpilih, tujuannya untuk memperoleh informasi prevalensi balita stunting(Kemenkes RI, 2014).

Kartu Menuju Sehat yang digunakan untuk memantau pertumbuhan, dibuat berdasarkan standar baku WHO antro 2005 dengan menggunakan indeks Berat Badan menurut Umur (BB/U). Indeks ini tidak dapat memantau kejadian stunting pada balita. Sehingga perlu adanya KMS berdasarkan indeks Tinggi Badan atau Panjang Badan menurut Umur (TB-PB/U) yang dapat digunakan untuk mendeteksi kejadian stunting pada anak balita. (Kemenkes, 2010) Diharapkan melalui kelompok pemberdayaan, masyarakat tahu dan menganggap stunting sebagai suatu masalah, agar mereka memiliki motivasi untuk melakukan pencegahannya pada tingkat rumah tangga dan memanfaatkan layanan yang tersedia untuk meningkatkan pertumbuhan dan perkembangan anak (WHO,2013) Melalui kader yang dipilih oleh masyarakat, dapat membantu mengidentifikasi masalah, mengembangkan kapasitas agar masyarakat dapat menangani masalah yang dihadapi secara lebih efektif, untuk itu kader perlu memiliki pengetahuan dan keterampilan dalam melaksanakan kegiatannya.

\section{METODE}

Sasaran kegiatan ini adalah Kader Posyandu yang nantinya melaksanakan pemantauan stunting pada anak balita karena memiliki komitmen untuk pelaksanaan kegiatan penurunan prevalensi stunting, Penjelasan modul oleh Tim Pengabmas, dilanjutkan review modul oleh kader selama 1 minggu kemudian dilakukan evaluasi akhir. 


\section{HASIL DAN PEMBAHASAN}

\section{a. Modul dan Sasaran}

Modul terdiri dari 3 modul yaitu, faktor penyebab kejadian stunting pada balita dan dampaknya, perhitungan umur, teniknik pengukuran panjang dan tinggi badan balita dan Penilaian dan pemantauan stunting pada balita.

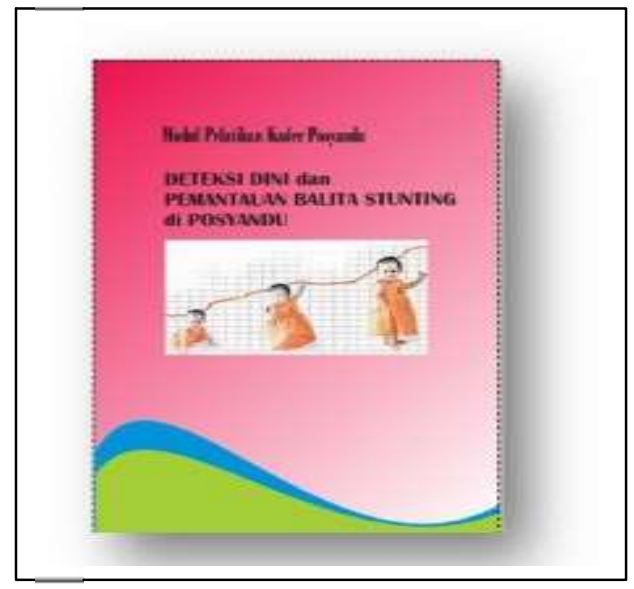

Jumlah sasaran yang hadir pada awal kegiatan atau pada saat uji coba modul banyak 21 kader yang tersebar dari beberapa posyandu di desa Cipeujeh Wetan. Tetapi pada saat posttest yang dilakukan seminggu setelah pelatihan yang hadir hanya 15 orang kader dan 3 orang dari tenaga puskesmas yaitu bidan coordinator, tenaga promkes dan bidan desa. Kader yang mengikuti pretest dan postets memiliki tingkat pendidikan yang beragam lebih jelasnya pada tabel 1.

$\underline{\text { Tabel 1,Tingkat Pendidikan Kader Posyandu di Desa Cipeujeuh Wetan }}$

\begin{tabular}{lrr} 
Tingkat Pendidikan & f & \% \\
\hline SD & 1 & 6.7 \\
SMP & 5 & 33.3 \\
SMA & 8 & 53.3 \\
Sarjana & 1 & 6.7 \\
\hline Total & 15 & 100.0 \\
\hline
\end{tabular}

Umumnya (53,3\%) tingkat pendidikan kader yang mengikuti uji coba modul adalah SMA, dengan usia berkisar antara 31 sampai dengan 60 tahun. Setelah diklasifikasikan hasilnya pada tabel .2 
Tabel 2, Umur Kader Posyandu di Desa Cipeujeuh Wetan yang Mengikuti Uji Coba Modul.

\begin{tabular}{|c|c|c|}
\hline Umur & $\mathbf{f}$ & $\%$ \\
\hline$<40$ Tahun & 4 & 26.7 \\
\hline 41 - 50 Tahun & 5 & 33.3 \\
\hline > 50 Tahun & 6 & 40.0 \\
\hline Total & 15 & 100.0 \\
\hline
\end{tabular}

Kader yang mengikuti uji coba modul umunya berusia 50 tahun keatas atau sebesar $40 \%$.

\section{b. Penilain Kader Terhadap Modul Secara Umum.}

Penilaian secara keseluruhan oleh kader terhadap modul tentang kesesuaian judul dengan isi materi. Opsi pilihan ada 4 yaitu sangat sesuai, sesuai, kurang sesuai dan tidak sesuai hasilnya pada tabel 3 .

Tabel 3, Penialain Kader Posyandu Terhadap Isi Modul.

\begin{tabular}{|c|c|c|c|}
\hline \multirow{2}{*}{$\begin{array}{l}\text { Tingkat } \\
\text { Pendidikan } \\
\text { Kader }\end{array}$} & \multicolumn{2}{|c|}{ Kesesuaian Judul dengan Isi Materi } & \multirow{2}{*}{$\begin{array}{l}\text { Total } \\
\text { n(\%) }\end{array}$} \\
\hline & $\begin{array}{c}\text { Sangat Sesuai } \\
n(\%)\end{array}$ & $\begin{array}{l}\text { Sesuai } \\
\mathrm{n}(\%)\end{array}$ & \\
\hline SD & $0(0.0)$ & $1(100.0)$ & $1(100.0)$ \\
\hline SMP & $0(0.0)$ & $5(100.0)$ & $5(100.0)$ \\
\hline SMA & $1(12.5)$ & $7(87.5)$ & $8(100.0)$ \\
\hline Sarjana & $0(0.0)$ & $1(100.0)$ & 1(100.0) \\
\hline Total & $1(6.7)$ & $14(93.3)$ & $15(100.0)$ \\
\hline
\end{tabular}

Umumnya $(93,3 \%)$ menilai sesuai antara Judul pokok bahasan dengan isi modul 


\section{c. Pemahaman Kader Setiap Modul}

Modul 1 Faktor Penyebab Kejadian Stunting pada Balita dan Dampaknya .

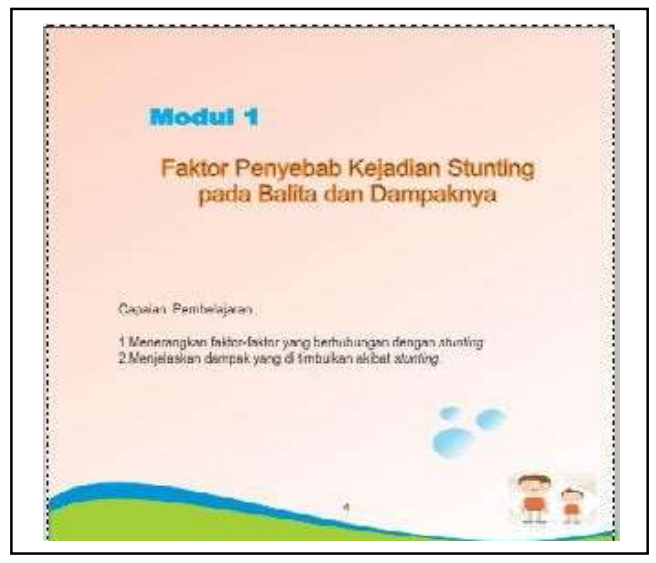

Modul 1 membahas tentang Faktor penyebab Stunting pada balita dan dampak akibat stunting diusia balita. Hasil penilaian kader terhadap modul satu, setelah kader membaca semuanya mengatakan mudah dipahami.

\section{Modul 2 Cara Perhitungan Umur dan Teknik Pengukuran Panjang/Tinggi Badan Balita}

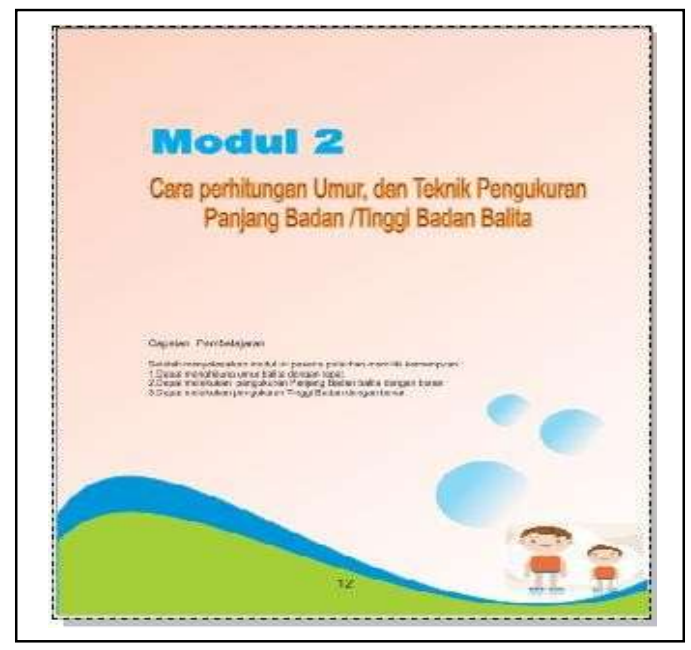

Modul 2 merupakan keterampilan yang harus dimiliki kader sebelum melakukan penilaian dan pemantauan stunting pada balita. Penilaian kader terhadap pemahaman modul lebih jelasnya pada tabel 4 . 
Tabel 4 Pemahaman Kader Terhadap Isi Modul 2

\begin{tabular}{lrrr}
\hline \multirow{2}{*}{$\begin{array}{l}\text { Tingkat } \\
\text { Pendidikan }\end{array}$} & \multicolumn{2}{c}{ Pemahaman Isi Modul } & Tudah \\
\cline { 2 - 3 } & $\begin{array}{c}\text { Mudah } \\
\text { dipahami } \mathbf{n}(\%)\end{array}$ & $\begin{array}{c}\text { Sulit dipahami } \\
\mathbf{n}(\%)\end{array}$ & \\
\hline SD & $0(0,0)$ & $1(100,0)$ & $1(100.0)$ \\
SMP & $4(80,0)$ & $1(20,0)$ & $5(100,0)$ \\
SMA & $7(87,5)$ & $1(12,5)$ & $8(100,0)$ \\
Sarjana & $0(0,0)$ & $1(100,0)$ & $1(100,0)$ \\
\hline Total & $11(73,3)$ & $4(26,7)$ & $15(100,0)$ \\
\hline
\end{tabular}

Sebanyak 73,3\% kader mengatakan mudah memahami isi dari modul 2 dan 26,7\% mengatakan sulit dipahami. Setelah dilakukan focus group discussion untuk mengetahui konten yang sulit dipahami, ternyata adalah perhitungan umur dengan metode 2 yaitu perhitungan dengan cara bila hasil pengurangan antara tanggal ukur dan tanggal lahir minus atau pengurangan tanggal ukur lebih besar dari tanggal lahir sehingga harus meminjam 1 bulan (30 hari) dan selanjutnya bila bulan pengukuran lebih besar dari bulan kelahiran makan harus meminjam satu tahun, perhitungan ini sulit dipahami. Perhitungan umur menggunakan metode 1 yaitu pengurangan secara langsung tanpa peminjaman bulan dan tahun yang mudah dipahami.

Modul 3. Penilaian dan Pemantaun Stunting pada Balita di Posyandu

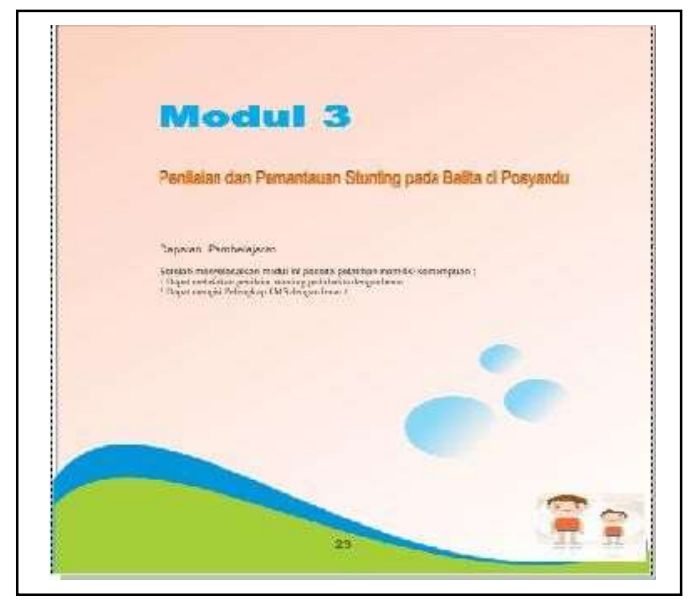

Modul 3,tentang keterampilan yang harus dimiliki oleh kader, tentang cara penilaian stunting dan pengisian Pelengkap Kartu Menuju Sehat (PKMS. Penilaian dan PKM 
stunting balita merupakan hasil karya dari Samuel, Prodi Gizi Cirebon Poltekkes Kemenkes Tasikmalaya. Penilaian stunting pada balita dibuat secara sederhana yang mudah dikerjakan oleh kader. Pemantauan stunting menggunakan PKMS dibuat untuk anak usia 0 bulan sampai 24 bulan, dengan alasan usia tersebut termasuk dalam 1000 hari kehidupan. Desain PKMS disesuaikan dengan KMS balita yang biasa digunakan kader di posyandu. Hasil penilaian kader terhadap modul 3 semuanya mengatakan mudah dipahami.

\section{d. Penilaian Keberlanjutan Modul dan Program Penilaian dan Pemantauan Stunting}

Hasil penilaian kader posyandu tentang pentingnya modul hasilnya pada tabel5.

Tabel 5 Pentingnya Modul bagi Kader Posyandu

\begin{tabular}{lccc}
\hline \multirow{2}{*}{$\begin{array}{c}\text { Tingkat } \\
\text { Pendidikan }\end{array}$} & \multicolumn{2}{c}{ Penting_Modul } & \\
\cline { 2 - 3 } & Sangat Penting & Penting & Total \\
& $\mathbf{n}(\boldsymbol{\%})$ & n $(\boldsymbol{\%})$ & $1(100,0)$ \\
\hline SD & $1(100,0)$ & $0(0,0)$ & $5(100,0)$ \\
SMP & $2(40,0)$ & $3(60,0)$ & $8(100,0)$ \\
SMA & $6(75,0)$ & $2(25,0)$ & $1(100,0)$ \\
Sarjana & $1(100,0)$ & $0(0,0)$ & $15(100,0)$ \\
\hline Total & $10(66,7)$ & $5(33,3)$ & \\
\hline
\end{tabular}

Sebanyak 66,7\% kader menilai modul sangat penting bagi mereka dan hanya 33,3\% yang mengatakan penting. Pentingnya kegiatan deteksi dini stunting di posyandu hasilnya pada tabel 6.

Tabel 6 Perlunya deteksi dini kejadian Stunting di Posyandu

\begin{tabular}{lcrr}
\multirow{2}{*}{ Tingkat } & \multicolumn{2}{c}{ Perlunya Deteksi Dini } & \\
\cline { 2 - 3 } \multicolumn{1}{c}{ Pendidikan } & $\begin{array}{c}\text { Sangat Perlu } \\
\text { n(\%) }\end{array}$ & $\begin{array}{c}\text { Potal } \\
\text { n(\%) }\end{array}$ & \\
\hline SD & $0(0,0)$ & $1(100,0)$ & $1(100,0)$ \\
SMP & $1(20,0)$ & $4(80,0)$ & $5(100,0)$ \\
SMA & $7(87,5)$ & $1(12,5)$ & $8(100,0)$ \\
Sarjana & $0(0,0)$ & $1(100,0)$ & $1(100,0)$ \\
\hline Total & $8(53,3)$ & $7(46,7)$ & $15(100,0)$ \\
\hline
\end{tabular}


Umumnya (53,3\%) menilai sangat perlu dan 46,7 \% menilai perlu dilaksanakan deteksi dini kejadian stunting di Posyandu.

\section{e. Faktor Pendukung dan Kendala}

Sarana prasarana yang digunakan dalam penilaian dan pemantauan stunting di posyandu seperti mikrotoice, length board merupakan alat yang biasa digunakan pada saat Bulan Penimbangan Balita (BPB) sehingga bukan hal yang baru bagi kader. Dalam pelaksanaan kegiatan dukungan Puskesmas Sindanglaut dan Bidan Desa serta kepala desa Cipeujeuh kulon sangat baik.Berdasarkan penilaian kader tentang pentingnya Deteksi Dini Kejadian Stunting di Posyandu maka perlu ditindaklajuti oleh puskesmas dan dinas kesehatan melalui pelatihan, pembuatan modul, dan penggandaan penilaian stunting dan PKMS di posyandu.

\section{SIMPULAN}

a. Umumnya $(53,3 \%)$ kader memiliki tingkat pendidikan SMA, dengan usia berkisar antara 31 sampai dengan 60 tahun.

b. Sebanyak 93,3\% kader menilai sesuai antara Judul pokok bahasan dengan isi modul, semua kader dapat memahami modul 1, sebanyak 73,3\% dapat memahami isi dari modul 2 dan semua kader pada memahami modul 3.

c. Sebanyak $67,7 \%$ kader posyandu menilai modul sangat penting dan hanya $33,3 \%$ yang mengatakan penting. 53,3\% kader mengatakan sangat perlu dan 46,7 \% mengatakan perlu dilaksanakan deteksi dini kejadian stunting di Posyandu.

\section{REFERENSI}

Bove Isabel. Stunting, overweight and child development impairment go hand in hand as key problems of early infancy: Uruguayan case. Early Human Development. 2012; 88 $747-751$.

Litbangkes. Riset Kesehatan Dasar 2010. Jakarta: Litbangkes, Departemen Kesehatan; $2010 ; 49$.

Litbangkes. Riset Kesehatan Dasar. Jakarta: Litbangkes, Departemen Kesehatan; 2013;252

RI Kemenkes. Pedoman Teknis Pemantauan Status Gizi M.Sc. DABJ, editor. Jakarta: Direktorat Bina Gizi; 2014.

RI Kemenkes. Permenkes No. 155/Menkes/Per/I/2010 tentang Penggunaan KMS Balita Jakarta: Kemenkes RI; 2010.UNICEF. Stunting Linked to Impaired Intellectual Development. http :www. unicef.org/sowc98/panel3.htm. 1998.

WHO. Childhood Stunting Challenges and opportunities. In WHO; 2013; Genewa. P: 2,15,16.

Yasmin Ghaida et.al. Risk Factors of Stunting among School-Aged Children from Eight Provinces in Indonesia. Pakistan Journal of Nutrition. 2014; 13 (10): 557-566. 